\title{
Effectiveness of Psycho-Spiritual Interventions on Emotional Intelligence and Psychological Resilience of Juvenile Delinquents
}

\author{
Seena. N. $\mathrm{S}^{1 *}$, Dr. Vidhya Ravindranadan ${ }^{2}$
}

\section{ABSTRACT}

The present study attempts to find out the efficacy of Psycho-spiritual interventions on emotional intelligence and psychological resilience among juvenile delinquents. Samples comprised of 5 delinquent boys who are remanded for commission of offenses of age 16-18 years, drawn through purposive sampling. Pre-test post-test experimental design is adopted. Psychological assessments are done using appropriate inventories for each variable. Interventions include Yoga, Super brain yoga, Meditations, CBT, cognitive re-structuring with mindfulness as the highlight and group counseling for 21 days over a period of 1 month. Paired sample t test was used to compare the pre test and post test scores. The outcome of the study substantiates the efficacy of the interventions for the enhancement of study variables among Juvenile delinquents.

Keywords: Juvenile delinquents, Emotional intelligence and psychological resilience, Psychospiritual interventions

"Every delinquent child is a victim of circumstances," the saying that is powerful enough to evoke the necessity of looking upon juvenile delinquency as an awe-inspiring pursuit. When the status of a 'free child' turns to that of a "juvenile delinquent", his or her dignity or self esteem spontaneously plummets. How well one can cope to this change, depends mainly on their psychological attributes like resilience and their intelligence variables like emotional quotient and spiritual quotient.

Juvenile delinquency etymologically is, participation in an illegal behaviour by a minor (individual younger than statutory age), which would have been charged as a crime if it were committed by an adult. According to the definition set forth by United Nations Convention for Right of the Child (UNCRC) recently they are grouped as, the children those are kept in juvenile

\footnotetext{
${ }^{1}$ Consultant Psychologist \& Doctoral Research Scholar, Research and Development Centre, Bharathiar University, Coimbatore, India

${ }^{2}$ Assistant Professor, Research and P.G. Dept. of Psychology, Union Christian College, Aluva, Kerala, India *Responding Author

(C) 2016, N Seena, V Ravindranadan; licensee IJIP. This is an Open Access Research distributed under the terms of the Creative Commons Attribution License (http://creativecommons.org/licenses/by/2.0), which permits unrestricted use, distribution, and reproduction in any Medium, provided the original work is properly cited.
} 


\section{Effectiveness of Psycho-Spiritual Interventions On Emotional Intelligence and Psychological Resilience of Juvenile Delinquents}

rehabilitation centers on being accused of the commission of crimes [1]. In India section 2(1) of the juvenile care and protection of children Act 2000, has coined the term Juvenile in conflict with law (JCL), as "one who is alleged to have committed an offense and has not yet completed $18^{\text {th }}$ year of age on the date of commission of such offense. Juvenile delinquent is retained in separate Juvenile Justice Institutions called Observation homes, which were previously known as remand homes. UNCRC, an internationally accredited document in the area of Child rights and Child protection has been ratified by nations worldwide, defines the age of criminal responsibility as an age below which a child cannot be responsible for any act committed by him. This goes well in tune with the opening statement and the gravity, which this intensely damaging social issue truly demands.

Psychological Resilience is defined as the capacity of the individual to effectively modulate and monitor an ever-changing complex of desires and reality constraints [2]. It is simplified as the ability to cope with stressors in life. In a study among adolescents of high caliber in education, having had experienced misbehavior argue that $21 \%$ of them had good social resilience. Such studies depict that being religious creates objectivity in adolescents despite their current problems. Some teenagers use their faith to create hope for improvement of condition in the future [3]. Effect of family, religious approaches and hope for the future are considered as potential protective factors of psychological resilience. Existing researches, examining the processing of emotional stimuli in depressed participants and in resilient participants might however; elucidate how emotion might specifically affect cognitive-behavioural processes in depressed individuals and in never-disordered individuals.

Emotional Intelligence signifies the ability to understand and manage ones as well as the others' emotions. It refers to a combination of skills these include empathy self control, self awareness, sensitivity to the feeling of others, persistence and self motivation among others [4]. The Greek Philosopher, Aristotle puts forward a right recipe for handling relations smoothly. He said that one must be able to be angry with the right person, to the right degree, at the right time, for the right purpose and in the right way. It is nothing but high quality of soft skills'.

All theories on psychological stress view that two concepts are central on deciding the level of stress experienced [5] one is Appraisal i.e., individual's evaluation of the significance of what is happening for their wellbeing [6] and the other is Coping i.e., individual's effort in thought and action to manage specific demands. The holistic perspective of yoga is to accept every experience of life (apparently rewarding or punishing) with equanimity as part of the integral whole contributing to a better awareness of self providing deeper insights leading one towards the real purpose of life. In other words every experience comes with a lesson to be imbibed and should be looked upon as an opportunity to learn, understand and evolve as a better self to a higher level of consciousness. 


\section{Effectiveness of Psycho-Spiritual Interventions On Emotional Intelligence and Psychological Resilience of Juvenile Delinquents}

OJJDP publication [7] on juvenile delinquency says intervention methods are required to prevent child delinquency from escalating into serious and violent juvenile offending which must address a range of risk and protective factors. Thus setup better moral and ethical values in life. This also helped in shaping at least some of them to better human and social beings. Meditations, Yoga therapy and psycho-therapy prepare them to cope better, with the stressors of life ahead to throw light upon their distorted cognitions. Create awareness about maladaptive thinking patterns, resultant negative behaviours, and subsequent harmful issues creating damages. To show the scope for a change, a positive change and boost inner strength to be virtuous through cognitive restructuring, and develop empathy towards the victim of the committed crime. Ultimately foster an integral perception of life.

\section{Objective}

The present study is intended upon to consider the possibilities to enhance the emotional intelligence and psychological resilience through psycho-spiritual interventions among juvenile delinquents.

\section{METHOD}

\section{Participants}

Samples are selected through purposive sampling method for the present study. They include 5 juvenile delinquents remanded in the Observation Home for boys (juvenile justice Institution under The Social Justice Department of the Government of Kerala.) for commission of serious offenses, in the age group between 16 and 18. All of them are school-dropouts, at high school level, and of comparable socio-economic status. The inclusion criteria are their nature of delinquency, (Using a checklist) [8] satisfactory mental and physical health, co-operation and willingness to change, Data drawn from interviews and other secondary data such as information from caretakers and medical records.

\section{Instruments}

The following instruments are used to collect data for the study.

a. Emotional Intelligence Inventory : Emotional Intelligence Inventory (EII) developed by Immanuel Thomas and Sushama [9] the questionnaire contains fifty items and a five-point response scale with points 5,4,3,2,1 ranging from completely agree to completely disagree. Twenty nine are positive items and twenty one are negative. For negative items the scoring is done in reverse order. The total score gives overall Emotional Intelligence Quotient. Apart from that sub score of items falling under factor I gives personal efficacy, factor II sub-score denotes Interpersonal efficacy and finally factor III sub scores point towards ones Intrapersonal efficacy. Reliability of the Emotional Intelligence Inventory has been established using Cronbach Alpha, the coefficient obtained is 0.88 and the questionnaire has found to have high content validity. 


\section{Effectiveness of Psycho-Spiritual Interventions On Emotional Intelligence and Psychological Resilience of Juvenile Delinquents}

b. Child and Youth Resilience Measure (CYRM-28) developed by the Resilience Research Centre in 2011 [10] is the instrument used to measure psychological resilience in the present study. It consists of 28 items elucidating their stress areas and how they validate various relationships- with parents, authorities, friends, with one self and how these relationships come to assistance in handling a crisis and stress coping. The responses to be given on a 5 point liker scale ranging from 'not at all true' of me, to 'a little', 'somewhat', 'quite a bit' finally to 'A lot.' The values allotted for the responses are from 1 to 5.1 given for 'not at all true' in ascending order to 5 given for 'a lot.' The summation of all 28 values gives the overall psychological resilience score of the individual. CYRM-28 has three subscales: Individual capacities and resources. (I score) , (scores of the items 2,4, 8, 11, 13,14,, 15,18, 20,21 and 25 ) The second subscale is (r score): Relationships with primary caregivers and the third (c score) Contextual factors that facilitate a sense of belonging. Higher the score, better the resilience. The reliability and validity tested, Cranach's alpha coefficient obtained 0.76 [10]

c. Demographic data sheet: A demographic data sheet has been prepared for the purpose of collecting data like age, education, Socio Economic status of the family and Occupation of the parent.

\section{PSYCHO-SPIRITUAL INTERVENTIONS}

The psycho- spiritual intervention designed is a combination of spiritual, yogic and psycho therapeutic practices. Indigenous healing practices like Thopukarnam (Super brain yoga), Meditation and Pranayama comprise the spiritual part.

To be conscious of our respiration, feel the air entering and leaving our body. [11]. the key factor of meditation is mindfulness i.e., being totally here and now relishing the present moment to its fullest. Meditations if ardently practiced in the right manner for a considerable duration can create structural changes in human brain that helps one evolve to a higher level of consciousness. Researches of Pert[12] Psycho neuro-immunologist suggests this, in her quote on Info realm referred to as a separate realm of connection between body and brain that links together and communicates with all cells in the body. Bodhi, R.Badami [13] observed 'The effectiveness of yoga on adolescent with developmental disabilities and found that yoga has been very effective for personality development”. Practice of these techniques helps to train the nervous system and produce physiological balance in different systems of human body and mind. Mindfulness is the key to the cognitive restructuring part of the cognitive behavioural therapy.

\section{Super brain yoga}

Inhale as slow as possible and squat down to ones comfortable range; with hands holding on to the opposite side earlobes crossing at the chest. Then come back to resume the position as you 


\section{Effectiveness of Psycho-Spiritual Interventions On Emotional Intelligence and Psychological Resilience of Juvenile Delinquents}

exhale. Repeat it for 3-5 minutes duration or for 15 to 20 times continuously. One can take pause for few seconds in between in case fatigue.

\section{Relaxation with white light meditation}

Progressively tense and relax each body part starting from left foot, right foot, left foreleg, right foreleg, left upper leg, right upper leg, buttocks, traversing up till back of the neck: progressively tensing for a count of 3 and progressively relaxing for the same count. (as in Jacobson's relaxation technique) At total relaxation visualize white light traversing to each part of the body deeply relaxing and healing it, right from foot to head.

\section{Pranayama}

Posture: Sit in a comfortable position in any asana posture on a mat on the floor, or in a chair. Keeping the body straight, hand resting on the knees, palms open and eyes closed.

Method Start up with long deep inhalation keeping a notice of time taken and exhale slowly chanting 'Om' spending exactly the same count. 3 cycles of 10 each, with a pause of 1-2 minutes between cycles.

\section{Mantra Yoga}

Posture: Same as pranayama

The chanting of cosmic mantra “OM” with split syllables of “a...”, “U....”and "um....”to a count in the ratio 1:2:4 respectively, synchronized with a single exhalation following a long deep inhalation. The ratio part brings in total mindfulness mentally chanting the mantra focusing between the eyebrows, at heart and at the navel.

\section{Meditation}

Posture: Same as above or lie down, in continuum with mantra chanting. Just observe the thoughts and let go. Do not forcefully push away, or be pulled along with it.

Mentally chanting the mantra focusing between the eyebrows. Just observes the thoughts, acknowledge and let go (any of these meditations, to be practiced daily with mindfulness). Deeper and longer guided meditations with music are given only once a week during tutorials.

Cognitive restructuring: The sessions imparting Integral perception and analyzing thought patterns, in group. Cognitive Behavioural Therapy is given with highlight in mindfulness.

Group and Individual counseling is overlapping with CBT, to help them positively look at the remand period as the inevitable effect of a committed crime undergone, and accepting themselves totally by inculcating value additions to their perceptions. To provide with effective coping strategies to overcome associated negative emotions like hurt, despair, rejection, vengeance, lack of forgiveness and hate for the world. It is aimed at imparting soft- skills and positive qualities to look at incidents from a different angle, bring awareness to the problems 


\section{Effectiveness of Psycho-Spiritual Interventions On Emotional Intelligence and Psychological Resilience of Juvenile Delinquents}

related to maladaptive thinking patterns, consequential negative emotions and to replace these with acceptance, forgiveness and constructive coping strategies. Counseling takes into consideration, the orientation of the individual and the group. One session per sample was given if required, to tackle their specific problems and emotional requirements, and general problems were addressed in the group sessions.

\section{Schedule}

Intervention was given for a period of 21Days (Approximately 4 hrs a day except Sunday's tutorial) Given with follow-up instructions for daily practice, about an hour altogether. Every training session started with Super brain yoga for 5 minutes duration. The instruction for follow up is to do the cycles regularly in the mornings for 3-5 min. or 15 times. The second in line comes relaxation with white light meditations of about 10 minutes. Omkar pranayama posture with a straight spinal column, observing and feeling the coolness and warmth of respiration (common for pranayama, 'Om' and other meditations) Takes approximately 15 to $20 \mathrm{~min}$. suggested regular practice in the mornings. For Om meditations, 10 minutes of abdominal breathing is recommended. A session of 20-25 minutes is advised to be set apart for meditations regularly preferably in the mornings after pranayama or Om chanting.

\section{PROCEDURE AND STATISTICAL ANALYSIS}

Pre-test post-test experimental design is the research method is adopted. After doing the pre test on the study variables Emotional Intelligence and Psychological Resilience, Psycho-spiritual interventions are given for a period of 21 days over a period of one month. Experimenter, who is also a yoga and spiritual trainer, imparted the training on psycho-spiritual techniques, for duration of 4 hours per day for 21 days, with instructions for daily practice and schedule for follow up. This is to aid them, in developing an insight on their delinquent nature, address potential risks involved in their thus projected future. At the end of intervention period, post-test was conducted. The pre test and post test scores were compared using paired sample t-test in SPSS.

\section{RESULT AND DISCUSSION}

The statistical method used in analyzing the data is Paired sample ' $\mathrm{t}$ ' test and the results are given in Table: 1

Table: 1 Comparison of pre test and post test scores on study variable

\begin{tabular}{|l|l|c|c|c|c|}
\hline \multicolumn{1}{|c|}{ Variables } & \multicolumn{1}{|c|}{ Scores } & Mean & N & Standard deviation & t value \\
\hline $\begin{array}{l}\text { Personal } \\
\text { Efficacy }\end{array}$ & Pre Test & 67.40 & 5 & 5.863 & \\
\cline { 2 - 7 } $\begin{array}{l}\text { Interpersonal } \\
\text { Efficacy }\end{array}$ & Post test & 107.40 & 5 & 18.093 & $30.679^{* *}$ \\
\cline { 2 - 7 } & Pre-test & 29.20 & 5 & 18.838 & \\
\hline
\end{tabular}

(C) The International Journal of Indian Psychology, ISSN 2348-5396 (e)| ISSN: 2349-3429 (p) | 65 


\section{Effectiveness of Psycho-Spiritual Interventions On Emotional Intelligence and Psychological Resilience of Juvenile Delinquents}

\begin{tabular}{|l|l|c|l|c|c|}
\hline \multicolumn{1}{|c|}{ Variables } & \multicolumn{1}{|c|}{ Scores } & Mean & $\mathbf{N}$ & Standard deviation & t value \\
\hline Intrapersonal & & & & & \\
Efficacy & Pre-test & 22.40 & 5 & 6.819 & \\
\cline { 2 - 6 } $\begin{array}{l}\text { Total Emotional } \\
\text { Quotient }\end{array}$ & Post-test & 47.60 & 5 & 8.520 & $18.093^{* *}$ \\
\cline { 2 - 6 } $\begin{array}{l}\text { Individual } \\
\text { Component }\end{array}$ & Pre-test & 117.00 & 5 & 11.072 & \\
\hline Pest-test & 199.20 & 5 & 11.256 & $18.838^{* *}$ \\
\cline { 2 - 6 } $\begin{array}{l}\text { Component } \\
\text { Belongingness }\end{array}$ & Post-test & 24.20 & 5 & 7.362 & \\
\cline { 2 - 6 } Component & Pre-test & 17.20 & 5 & 3.114 & $7.278^{* *}$ \\
\hline \multirow{2}{*}{$\begin{array}{l}\text { Psychological } \\
\text { Resilience total }\end{array}$} & Pre-test & 31.40 & 5 & 2.472 & \\
\cline { 2 - 6 } & Post-test & 19.40 & 5 & 3.130 & \\
\cline { 2 - 6 } & Pre-test & 47.40 & 5 & 7.057 & $8.520^{* *}$ \\
\hline
\end{tabular}

** Significant at 0.01 level

Paired sample t test has been done to find out the mean difference of pre-test and post-test scores of all the study variables. From the results, the t-value of 30.679 for Personal efficacy was found significant at 0.01 levels. Thus the pre-test and post-test scores are significantly different. Comparing the mean values it becomes very clear that the post-test scores are significantly higher than the pre-test scores. This substantiates the fact that the Personal Efficacy, the first subset of Emotional Intelligence is considerably enhanced as a result of psycho-spiritual interventions among juvenile delinquents. The t- values of Inter personal efficacy and Intra personal efficacy are 5.863 and 18.093 respectively. These point out to the fact that the efficacy of psycho-spiritual intervention is significantly contributing to an increased Interpersonal and Intrapersonal efficacies, the second and third subsets of Emotional Intelligence Quotient. The mean difference of the pre-test and post test scores of Total Emotional Quotient is clear in the table as' t' value of 18.838 significant at 0.01 level. On comparison of the pretest and posttest scores, of the mean values of all the variables vouch on the efficacy of psycho-spiritual interventions in enhancing considerably the Emotional intelligence quotient and it's all subcomponents of juvenile delinquents.

The mean difference between pre-test and post-test scores of the subset individual component of the Psychological Resilience is highly significant at 0.01 levels. The mean value of the post test score is on the higher side which emphasizes that the psycho-spiritual interventions has been effective in bringing about a positive significant change in this area. The t value obtained from pre and post test mean values for the relationship component, the second subset of psychological resilience is 6.819 , marked as highly significant at 0.01 levels. Table gives $t-$ value $=8.520$ for belongingness component as a subset of psychological resilience as denoting the difference between pre and post-test scores. When we compare the mean values of pretest and post test scores for Total Psychological Resilience, post test shows a significant rise. The mean difference 


\section{Effectiveness of Psycho-Spiritual Interventions On Emotional Intelligence and Psychological Resilience of Juvenile Delinquents}

or t value is 11.072 , which is highly significant at 0.01 levels. The higher values for the post test scores and highly significant $t$ values, for Total Psychological Resilience and all the three subsets- individual (i score), relationship score( $\mathrm{r}$ score) and belongingness score(c score), substantiates the fact that the Psycho-spiritual interventions has been highly effective in enhancing Psychological Resilience.

Result of the present study supports the study done by Bodhi, R.Badami [13], who observed "The effectiveness of yoga on adolescent with developmental disabilities and found yoga is very effective for personality development”. Practice of these techniques helps to train the nervous system and produce physiological balance in different systems of human body and mind. Mindfulness is the key to the cognitive restructuring part of the cognitive behavioural therapy Researches conducted in the same line echoes the findings of the present study.

Enhancement of these variables would prevent from falling back again into the vicious cycle because of distorted cognitions which could lead to increase in the psychological setbacks maladaptive behaviour, associated diseases and disorders. In order to reduce the use of these errors is necessary to avoid labeling problematic individuals accepting them as they are. [14]. Practicing mindfulness techniques (meditation, yoga, body scan, stress management, etc.), increases the ability to tolerate negative emotional states and makes them ready to deal effectively with reduced stress maladaptive coping strategies. [15]

\section{CONCLUSION}

The finding of the present study analyzes the effectiveness of the spiritual and psychotherapeutic training program on Psychological resilience and Emotional Intelligence. Pre-test post-test experimental method is adopted. The intervention training program is imparted on the sample group of juvenile delinquents selected through purposive sampling. The interventions comprised of meditations, Yoga therapy and psycho therapy. Pre and post assessments of the scores on study variables were taken using appropriate and standardized instruments. Paired sample $t$ test is the method adopted for statistical analysis. Results of the analysis clearly depicts that a highly significant difference was brought about in the study variables- an increase was found in the scores of Emotional Intelligence and Psychological resilience and the three sub factors of each. Findings substantiate that the study variables and all the sub factors of EQ and resilience of Juvenile delinquents are significantly enhanced through psycho-spiritual interventions and thus the intervention can be considered as highly effective.

\section{Acknowledgments}

The authorities and appreciates all those who participated in the study and helped to facilitate the research process. 


\section{Effectiveness of Psycho-Spiritual Interventions On Emotional Intelligence and Psychological Resilience of Juvenile Delinquents}

\section{Conflict of Interests}

The author declared no conflict of interests.

\section{REFERENCES}

1. W_H_O_(2001) World Health Report 2001 WHO: Geneva.

2. Block.J and Kremen. A. M (1996) IQ and ego-resiliency: Conceptual and empirical connections and seperatedness. Journal of Personality and Social Psychology. 79, 131-142.

3. Kaufman, J. Cook, A, Arny, L, Jones, B and Pittinsky, T. (1994). Problems defining resiliency: Illustrations from the study of maltreated children. Development and psychopathology, 1994:6, 215-229.

4. Salovey. P, Mayer J.D, (1990). Emotional intelligence: Imagination, Cognition and Personality. $\quad$ 9, $185-211$.

5. Lazarus,R.S, Kanner, A.D., \& Folkman, S . (1980). Emotions: A cognitivephenomenological analysis In R. Plutchik \& H. Kellerman (Eds), Theories of emotion. (pp. 189- 217) New York Academic Press

6. Ciarrochi, J., Chan, A. and Bajgar, J. (2001). Measuring Emotional Intelligence in adolescents. Personality and Individual Differences, 31(7), 1105-1119

7. Gail. A. Wasserman et. al (2003) Risk and protective factors of Child delinquency: Office of Juvenile Justice and Delinquency Prevention (OJJDP) publication. Bulletin series April 2003 at ojjdp.ncjrs.org.

8. Starke. R. Hathaway and Elio.D.Monachesi (2006) The prediction of Juvenile Delinquency using the Minnesota Multiphasic Personality Inventory. The American journal of Psychiatry 2006. From http://dx.doi.org/10.1176/ajp.108.6.469.

9. Thomas Immanuel and Sushama .S.R (2003). Emotional Intelligence Inventory; Manual. Department of Psychology, University of Kerala, Thiruvananthapuram, Kerala.

10. Ungar, M. and Liebenberg, L.(2011). Assessing resilience across cultures using mixedmethods. Construction of Child and Youth Resilience Measure-28. Journal of Mixed Methods Research, 5(2), 126-149.

11. Eckhart Tolle (2009) and Blaschke, Jorge. 2011; In Beyond the power of now. pp 126-157.

12. Pert, C (1997). Molecules of emotion.: The science behind body-mind medicine. New York, NY: Scribner.

13. Bodhi, R.Badami ( 2004) cited by Joshi Vimla and Pandya Pranav (2009) in PhD thesis on A study of the effect of psycho-spiritual package on loneliness, insecurity and Emotional intelligence in street children .Retrieved from http://shodhganga@inflibnet on August 2014.

14. Sehgal, Meena (1999). A study of emotional intelligence quotient, personality and psychological well-being of adolescents. A study of emotional intelligence quotient, personality and psychological well-being of adolescents. Asian Journal of Psychology and Education, 32 (1\& 2), 17-19. 


\section{Effectiveness of Psycho-Spiritual Interventions On Emotional Intelligence and Psychological Resilience of Juvenile Delinquents}

15. Ma, SF., Teasdale, JD. (2004). Mindfulness-based cognitive therapy for depression: Replication and exploration of differential relapse prevention effects. Journal of consulting and clinical psychology, 72(3): 31-40.

How to cite this article: N Seena, V Ravindranadan (2016), Effectiveness of Psycho-Spiritual Interventions On Emotional Intelligence and Psychological Resilience of Juvenile Delinquents, International Journal of Indian Psychology, Volume 3, Issue 4, No. 74, ISSN:2348-5396 (e), ISSN:2349-3429 (p), DIP:18.01.027/20160304, ISBN:978-1-365-46362-4 